\title{
Value of Nailfold Capillaroscopy as A Screening Method for Pulmonary Arterial Hypertension in Patients with Systemic Sclerosis \\ Rasha M. Hammoda ${ }^{1}$, Yasmin Abdelrazek Ali ${ }^{2}$, Nermeen Samy*1 \\ ${ }^{1}$ Department of Internal Medicine and Rheumatology and ${ }^{2}$ Department of Cardiology, of Medicine, Ain Shams University, Cairo, Egypt \\ *Corresponding author: Nermeen Samy, Mobile: 01223744672, Email: dr.nermeen81@ gmail.com
}

\begin{abstract}
Background: Pulmonary arterial hypertension (PAH) represents one of the main clinical pictures of microvascular damage in systemic sclerosis (SSc).

Objective: To assess the role of nailfold capillaroscopy (NFC) changes as a screening tool for the existence of PAH in patients with systemic sclerosis.

Patients and methods: Forty SSc patients were studied, included: 20 patients with PAH (diagnosed by transthoracic echocardiography and confirmed by right heart catheterization) and another 20 without PAH. History taking, clinical examination, and laboratory investigations including serological biomarkers (anti-centromere and anti-topoisomerase 1 antibodies) have been recorded. NFC was performed for all patients according to the standard method.

Results: Scleroderma patients with PAH had significantly a longer disease duration $(\mathrm{p}=0.002)$ and higher frequencies of positive anticentromere and anti-topoisomerase 1 antibodies $(\mathrm{p}=0.011$ and $\mathrm{p}=0.010$ respectively). As regard NFC picture, SSc patients without PAH had significantly higher frequencies of early scleroderma pattern changes in $73.7 \%$ $(\mathrm{p}=0.003)$, avascular area score 0 in $52.6 \%(\mathrm{p}=0.014)$ and total NFC score 0 in $57.9 \%(\mathrm{p}=0.022)$. In contrast, SSc patients with PAH showed higher frequencies of late scleroderma pattern changes in $50 \%(\mathrm{p}=0.005)$ with lower capillary density ( $\mathrm{p}<0.001)$, increased number of dilated mega-capillaries $(\mathrm{p}=0.049)$ together with more advanced avascular area of score 3 in $47.6 \%(\mathrm{p}=0.007)$ and total NFC of score 3 in $45 \%(\mathrm{p}=0.003)$. A significant negative correlation between mean pulmonary arterial pressure and capillary density $(\mathrm{r}=-0.57, \mathrm{p}<0.001)$ was reported.

Conclusion: Low capillary density together with wide avascular areas and more severe NFC scores have a clear association with the presence of PAH.
\end{abstract}

Keywords: Systemic Sclerosis, Pulmonary Arterial Hypertension, Nailfold capillaroscopy.

\section{INTRODUCTION}

Systemic sclerosis ( $\mathrm{SSc}$ ) is a long term complex autoimmune illness that still poses a great challenge to clinicians ${ }^{(\mathbf{1})}$. Autoimmunity, skin together with internal organs fibrosis, and vasculopathy are marked features ${ }^{(2)}$. Scleroderma is more common in women than men with male:female ratio equals $4-5: 1$. The average age of disease diagnosis is nearly 50 years ${ }^{(3)}$. The medical disease is classified according to the degree of skin affection into subclasses with diffuse cutaneous involvement (dcSSc) and limited cutaneous involvement $(\mathrm{lcSSc})^{(4)}$. Systemic sclerosis is marked by early and progressive microvascular distortion which can lead to fatal organ disorders of SSc, such as pulmonary arterial hypertension (PAH), scleroderma renal crisis, and tissue ischemia linked to organ dysfunction and fibrosis ${ }^{(5)}$. Egyptian SSc patients are at an increased risk of subclinical atherosclerosis and peripheral arterial disease ${ }^{(6)}$ and interstitial lung disease (ILD) is a frequent consequence of PAH especially in dcSSc patients ${ }^{(7)}$. Therefore, improvement of vasculopathy in SSc patients is one of the key treatment targets ${ }^{(5)}$.

Pulmonary hypertension $(\mathrm{PH})$ is considered one of the main causes of mortality in patients with scleroderma. Scleroderma patients with $\mathrm{PH}$ had poorer outcome compared to those with idiopathic pulmonary hypertension ${ }^{(6)}$. The WHO has subtyped $\mathrm{PH}$ into 5 categories: (1) PAH, (2) PH with left-sided heart failure, (3) $\mathrm{PH}$ due to hypoxic lung illness, and (4) $\mathrm{PH}$ secondary to chronic thromboembolism ${ }^{(8)}$. Patients with scleroderma may develop type 1,2 , or $3^{\left({ }^{(9)}\right.}$. PAH is a common late complication of scleroderma, mainly in those with limited cutaneous disease and anticentromere antibodies ${ }^{(6)}$. PAH is a lethal and malignant manifestation of vasculopathy in SSc that causes a dramatic impact on prognosis; and thus, necessitates an early screening and management ${ }^{(4)}$. Circulating plasma levels of endothelin1 are elevated in patients with PAH and are raised in their pulmonary tissue; making this vasoconstrictor a potential target for therapeutic intervention ${ }^{(10)}$. Moreover, a high serum endothelin1 level was found in SSc with late nailfold videocapillaroscopy (NVC) pattern and visceral involvement ${ }^{(\mathbf{1 1})}$.

Nailfold video capillaroscopy is considered a useful safe non-invasive tool used in evaluation and follow-up of systemic rheumatic illnesses and constitutes one of the best assessment tools of microvascular defects in SSc. The capillary changes in SSc usually incorporate dilated and giant capillaries, capillary hemorrhages, disarrayed capillary loops, ramified/bushy capillaries, and capillary 
loss (12). Interestingly, the association between progressive capillaroscopic changes (detecting microvascular damage) and the presence of PAH were evaluated in the last few years ${ }^{(13)}$. It is now obvious that the severity of the microvascular damage as evaluated by NVC varies among SSc patients with and without PAH and associates with pulmonary hemodynamic parameters. Remarkably, in comparison with healthy controls, the same is correct for those with idiopathic $\mathrm{PAH}$, a state not known to have a characterizing systemic microvascular involvement ${ }^{(\mathbf{1 4})}$.

The current study aimed to assess the role of nailfold capillaroscopic (NFC) changes as a screening tool for the existence of PAH in patients with systemic sclerosis.

\section{PATIENTS AND METHODS}

In our cross-sectional study, we included 40 patients with SSc diagnosed according to the 2013 American College of Rheumatology/European League Against Rheumatism (ACR/EULAR) Systemic Sclerosis Classification Criteria (15). Patients were classified as diffuse (dSSc) or limited (1SSc) cutaneous SSc following the classification by Le Roy et al. ${ }^{(16)}$. Patients were enrolled from the Outpatient Clinic and the Inpatient Department of Rheumatology at Ain Shams University Hospital. Twenty patients with PAH were included; diagnosed by transthoracic echocardiography (TTE) and confirmed by right heart catheterization and another 20 patients without PAH were also recruited. Patients with previous pulmonary or venous thromboembolism, diabetes mellitus, systemic arterial hypertension, interstitial lung disease, any chest disease-causing chronic hypoxia, cardiac disease, or other concomitant connective tissue diseases were excluded.

Ethical approval: The study was approved by the Local Research Ethical Committee of Ain Shams University and followed the provisions of the Declaration of Helsinki in 1995.

Every patients signed an informed consent.

All Patients were subjected to careful history taking and clinical examination. Laboratory investigations included a complete blood picture (CBC), erythrocyte sedimentation rate (ESR), Creactive protein (CRP), anti-nuclear antibody (ANA), and anti-centromere and anti-topoisomerase 1 (anti-Scl 70) by indirect immunofluorescence assay.

Transthoracic echocardiography was done using two-dimensional, M-mode, color flow mapping, and spectral Doppler techniques. Special attention was paid for detection of tricuspid regurgitation, its degree, estimation of right ventricular systolic pressure (RVSP) using Bernoulli equation (PASP $=4 \times \mathrm{xV}$ (of peak TR velocity)+ right atrial pressure), right ventricle (RV) size, RV systolic function using fractional area change (
RV FAC $=100 \times($ RVED area - RVES area $) /$ RVED area) ${ }^{(17)}$, and pulmonary regurgitation for estimation of mean pulmonary arterial pressure (PAP) using Bernoulli equation (mean PAP $=4 x \mathrm{~V} 2$ (of peak PR velocity)+ right atrial pressure) (18). Patients with estimated RVSP $>35 \mathrm{mmHg}$ or mean PAP more than 25 $\mathrm{mmHg}$ were taken to the catheterization laboratory for invasive measurement of PAP. Mean PAP > or equal 25 with pulmonary capillary wedge pressure (PCWP) < or equal $15 \mathrm{mmHg}$ confirmed having $\mathrm{PAH}$ according to 2015 ESC/ERS guidelines for the diagnosis and treatment of pulmonary hypertension ${ }^{(19)}$.

Nailfold capillary microscopy was performed using a video capillaroscopy with a probe (magnification $\times 200$ ) according to the standard method (20). All images were collected and registered using a dedicated software system (Blu Vision). The following parameters were considered; Comment on the shape of the capillaries (normal hairpin, or abnormal shapes e.g. Branching capillaries or tortuous), the diameter of the capillaries (dilated loops if the diameter is $>20 \mu \mathrm{m}$ and mega capillaries if $\geq 50 \mu \mathrm{m}$ ), the capillary length (normal or elongated $\geq 300 \mu \mathrm{m}$ ), the mean capillary density (low capillary density is defined as a reduction of the number $<7 /$ linear $\mathrm{mm}$ ), and the avascular area (inter capillary distance $\geq 500 \mu \mathrm{m}$ ). The presence of micro hemorrhage and of morphological abnormalities such as; tortuous, bizarre, enlarged, and irregular distribution of capillary array were considered. A rating scale was adopted to score the changes: score 0: no changes, score 1: few ( $\leq 4$ alterations/linear $\mathrm{mm})$, score 2: between 4 and 6 alterations, score 3 : frequent ( $>6$ alterations $/ \mathrm{mm})^{(21)}$. The score system for avascular areas (a vascularity of the capillary bed) was graded as: grade $0=$ no obvious avascular area, grade $1=$ mild $(1$ or 2 discrete areas of vascular deletion), grade $2=$ moderate ( $>2$ discrete areas of vascular deletion), and grade 3 = severe (large, confluent avascular areas) ${ }^{(22)}$. The NFC findings were further classified into normal patterns or changes suggestive for SSc which include early pattern (few giant capillaries, few hemorrhages and no capillary loss), active pattern (numerous giant capillaries and micro hemorrhages, mild capillary architecture disturbance and moderate capillary loss), and late pattern (severe capillary loss with extensive avascular areas, disorganized capillaries and ramified capillaries) ${ }^{(23)}$.

\section{Statistical analysis}

The Statistical Package for the Social Sciences (SPSS 20) was used. Data were presented and a suitable analysis was performed. Unpaired Student T-test was used to compare two independent groups regarding quantitative data. The Chi-square was used to compare qualitative variables. Pearson's correlation coefficient (r) test was used to assess the degree of association between two sets of variables. P-value $<0.05$ was considered significant. 


\section{RESULTS}

The demographic data of the patients are presented in table 1. SSc patients with PAH had significantly a longer disease duration, more limited subtype (lcSSc), more evident peripheral vascular manifestations in the form of Raynaud's phenomenon, telangiectasia, digital ulcers and pitting scars, and higher frequencies of positive anti centromere and antiScl70.

Table (1): Comparison between scleroderma patients with or without pulmonary artery hypertension (PAH) according to various demographic, clinical and laboratory data

\begin{tabular}{|c|c|c|c|c|}
\hline \multirow{2}{*}{$\begin{array}{c}\text { Parameter } \\
\text { Mean } \pm \mathrm{SD}(\text { range }) \\
\text { or } \mathrm{n}(\%)\end{array}$} & \multicolumn{3}{|c|}{ SSc patients $(n=40)$} & \multirow[b]{2}{*}{$\mathrm{p}$} \\
\hline & $\begin{array}{c}\text { All } \\
(\mathrm{n}=40)\end{array}$ & $\begin{array}{l}\text { with PAH } \\
(\mathrm{n}=20)\end{array}$ & $\begin{array}{l}\text { without PAH } \\
(n=20)\end{array}$ & \\
\hline Age (years) & $\begin{array}{c}39.1 \pm 8.24 \\
(22-55)\end{array}$ & $\begin{array}{c}41.1 \pm 6.3 \\
(33-52)\end{array}$ & $\begin{array}{c}37.2 \pm 10.2 \\
(22-55)\end{array}$ & 0.26 \\
\hline Female :male & $\begin{array}{c}33: 7 \\
(82.5 / 17.5) \\
\end{array}$ & $\begin{array}{c}16: 4 \\
(80 / 20)\end{array}$ & $\begin{array}{c}17: 3 \\
(85 / 15)\end{array}$ & 0.68 \\
\hline Age at onset (years) & $\begin{array}{c}27.2 \pm 6.9 \\
(16.6-45.5) \\
\end{array}$ & $\begin{array}{c}25.2 \pm 6.2 \\
(16.6-37.1)\end{array}$ & $\begin{array}{c}29.2 \pm 7.5 \\
(18.2-45.5)\end{array}$ & 0.16 \\
\hline Disease duration (years) & $\begin{array}{c}15.4 \pm 8.4 \\
(2-43)\end{array}$ & $\begin{array}{c}21.4 \pm 10.4 \\
(5-43)\end{array}$ & $\begin{array}{c}9.3 \pm 6.5 \\
(2-22)\end{array}$ & 0.002 \\
\hline Clinical manifestations & & & & \\
\hline $\begin{array}{l}\text { lcSSc } \\
\mathrm{dcSSc}\end{array}$ & $\begin{array}{l}25(62.5) \\
15(37.5)\end{array}$ & $\begin{array}{c}17(85) \\
3(15)\end{array}$ & $\begin{array}{c}8(40) \\
12(60)\end{array}$ & $\begin{array}{l}<0.004 \\
<0.004\end{array}$ \\
\hline Raynaud's & $32(80)$ & $20(100)$ & $12(60)$ & $\mathbf{0 . 0 3 2}$ \\
\hline Pitting scar & $21(52.5)$ & $15(75)$ & $6(30)$ & 0.043 \\
\hline Digital ulcer & $15(37.5)$ & $11(55)$ & $4(20)$ & 0.022 \\
\hline Renal crisis & $3(7.5)$ & $2(10)$ & $1(5)$ & 0.548 \\
\hline Telangiectasia & $25(62.5)$ & $17(85)$ & $8(40)$ & 0.033 \\
\hline Esophageal dysmobility & $34(85)$ & $19(95)$ & $15(95)$ & 0.765 \\
\hline Arthritis/arthralgia & $25(62.5)$ & $15(75)$ & $10(50)$ & 0.102 \\
\hline Laboratory investigations & & & & \\
\hline Hemoglobin (g/dl) & $\begin{array}{c}10.6 \pm 1.2 \\
(7.9-13.9)\end{array}$ & $\begin{array}{l}10.1 \pm 0.7 \\
(8.9-11)\end{array}$ & $\begin{array}{c}11.1 \pm 1.8 \\
(7.9-13.9)\end{array}$ & $<0.03$ \\
\hline WBC $\left(10^{9} / 1\right)$ & $\begin{array}{c}7.1 \pm 2.5 \\
(3.4-11.8)\end{array}$ & $\begin{array}{c}7.6 \pm 2.8 \\
(3.4-11.8)\end{array}$ & $\begin{array}{c}6.5 \pm 2.1 \\
(3.5-10.6)\end{array}$ & 0.26 \\
\hline Platelets $\left(10^{9} / 1\right)$ & $\begin{array}{c}252.1 \pm 56.1 \\
(133-340)\end{array}$ & $\begin{array}{c}263.4 \pm 45.7 \\
(150-310)\end{array}$ & $\begin{array}{c}240.8 \pm 66.4 \\
(133-340)\end{array}$ & 0.33 \\
\hline $\operatorname{ESR}(\mathrm{mm} / 1 \mathrm{st} \mathrm{hr})$ & $\begin{array}{c}56.7 \pm 15.4 \\
(23-102)\end{array}$ & $\begin{array}{c}75.2 \pm 17.7 \\
(47-102) \\
\end{array}$ & $\begin{array}{c}38.2 \pm 13.1 \\
(23-65)\end{array}$ & $<0.001$ \\
\hline Anti-centromere & $21(52.5)$ & $15(75)$ & $6(30)$ & 0.043 \\
\hline anti-Scl70 & $17(42.5)$ & $13(65)$ & $4(20)$ & 0.004 \\
\hline ANA & $16(40)$ & $9(45)$ & $7(35)$ & 0.518 \\
\hline
\end{tabular}

SSc: systemic sclerosis, PAH: pulmonary artery hypertension, dcSSc: diffuse cutaneous involvement, lcSSc: limited cutaneous involvement, ESR: erythrocyte sedimentation rate, WBC: white blood cells, ANA: anti-nuclear antibody.

As regard NFC picture, SSc patients without PAH had a significantly higher frequency of early scleroderma pattern changes, avascular area score 0 , and total NFC score 0 . In contrast, SSc patients with PAH showed a higher frequency of late scleroderma pattern changes with a lower capillary density, increased capillary width, increased number of dilated mega-capillaries together with increased areas of capillary hemorrhages, and areas of sub-capillary venous plexuses (Figure 1 and 2). Furthermore, those with PAH had more advanced avascular areas of score 3 and total NFC of score 3 (Table 2). There were no significant differences in the NFC findings according to the gender or between the lcSSc and dcSSc subtypes. 


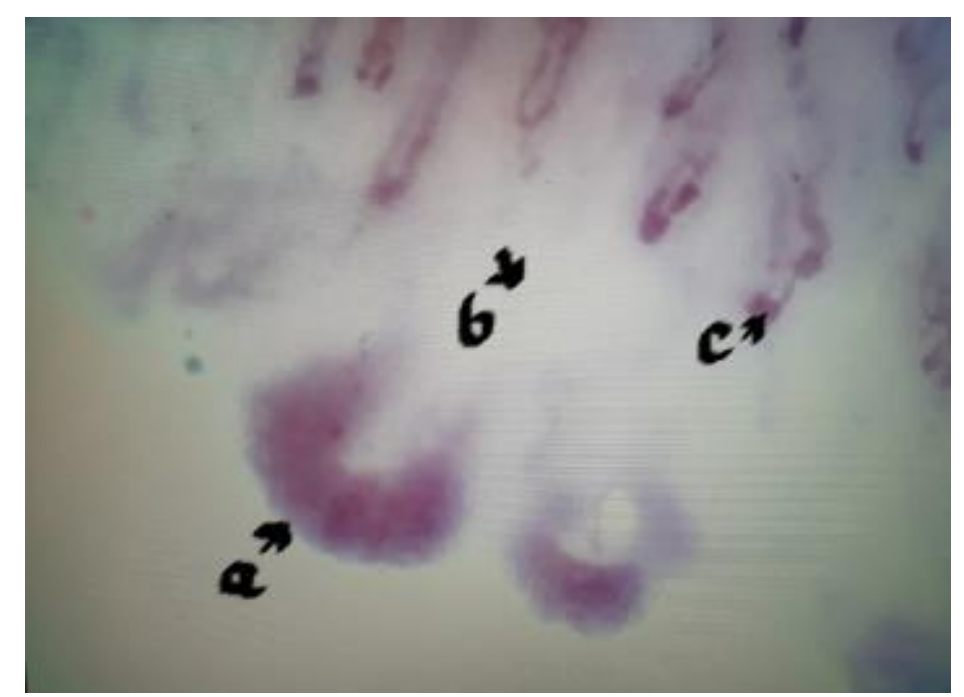

Figure (1): Nail fold capillaroscopy picture of systemic sclerosis patient with pulmonary arterial hypertension showing dilated capillary loops, giant capillaries, capillary hemorrhage and wide avascular area. a:giant capillary b:avascular area c:capillary hemorrhage

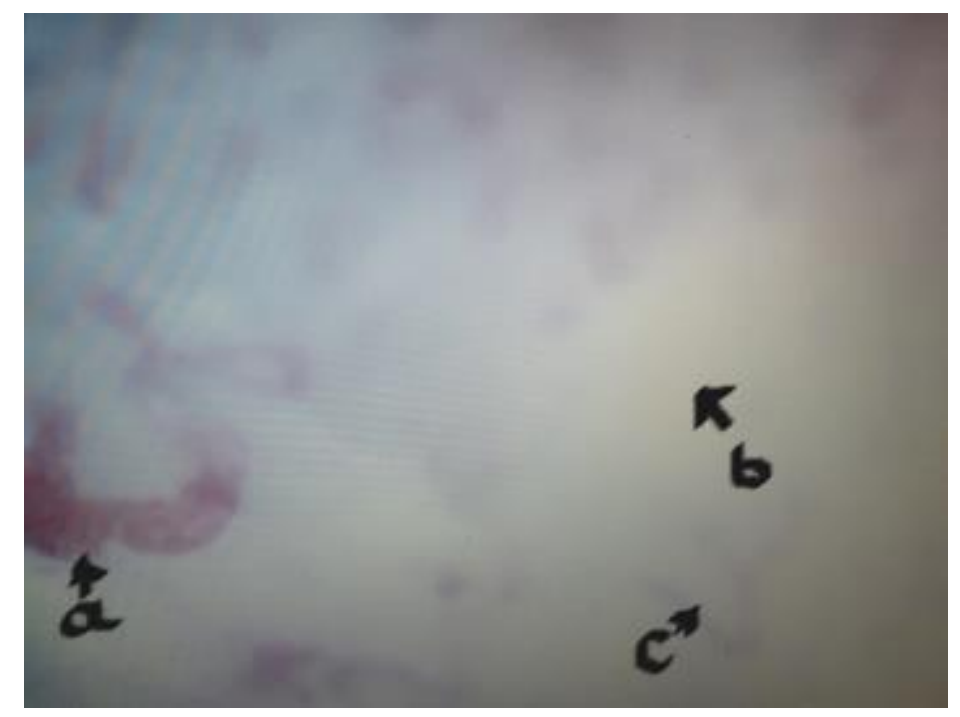

Figure (2): Nail fold capillaroscopy picture of systemic sclerosis patient with pulmonary arterial hypertension showing giant capillaries, wide avascular areas and telangiectasia (neoangiogenesis). a: giant loop b: avascular area c:neoangiogenesis. 
Table (2): Comparison between scleroderma patients with or without pulmonary artery hypertension (PAH) according to various nailfold capillaroscopy findings.

\begin{tabular}{|c|c|c|c|c|}
\hline \multirow{2}{*}{$\begin{array}{c}\text { Parameter } \\
\text { mean } \pm \mathrm{SD}(\text { range }) \\
\text { or } \mathrm{n}(\%)\end{array}$} & \multicolumn{3}{|c|}{ SSc patients $(n=40)$} & \multirow[b]{2}{*}{$\mathbf{P}$} \\
\hline & $\begin{array}{c}\text { All } \\
(\mathrm{n}=40)\end{array}$ & $\begin{array}{c}\text { with PAH } \\
(\mathrm{n}=20)\end{array}$ & $\begin{array}{l}\text { without } \\
(\mathrm{n}=20)\end{array}$ & \\
\hline Capillary density & $\begin{array}{c}7.6 \pm 1.4 \\
(5-10)\end{array}$ & $\begin{array}{c}6.6 \pm 1.3 \\
(5-8)\end{array}$ & $\begin{array}{c}8.6 \pm 1.6 \\
(7-10)\end{array}$ & $<0.001$ \\
\hline Capillary length & $\begin{array}{c}186.9 \pm 35.5 \\
(120-250)\end{array}$ & $\begin{array}{c}181.8 \pm 34.5 \\
(120-240)\end{array}$ & $\begin{array}{c}189.9 \pm 36.5 \\
(130-250)\end{array}$ & 0.475 \\
\hline Capillary width & $\begin{array}{c}40.4 \pm 7.7 \\
(20-60) \\
\end{array}$ & $\begin{array}{c}50.5 \pm 9.6 \\
(40-60)\end{array}$ & $\begin{array}{c}35.4 \pm 6.7 \\
(20-50) \\
\end{array}$ & $<0.001$ \\
\hline Capillary hemorrhage & $13(32.5)$ & $11(55)$ & $2(10)$ & 0.002 \\
\hline $\begin{array}{l}\text { Capillary shape } \\
\text { - Normal shape } \\
\text { - Dilated- mega-capillaries } \\
\text { - Tortuous capillaries } \\
\text { Sub- capillary venous plexus } \\
\end{array}$ & $\begin{array}{l}7(17.5) \\
28(70) \\
5(12.5) \\
26(65) \\
\end{array}$ & $\begin{array}{c}0(0) \\
18(90) \\
3(15) \\
18(90) \\
\end{array}$ & $\begin{array}{l}7(35) \\
10(50) \\
2(10) \\
8(10) \\
\end{array}$ & $\begin{array}{l}\mathbf{0 . 0 0 8} \\
\mathbf{0 . 0 0 6} \\
0.633 \\
\mathbf{0 . 0 0 1} \\
\end{array}$ \\
\hline $\begin{array}{l}\text { NFC pattern } \\
\text { Early } \\
\text { Active } \\
\text { Late }\end{array}$ & $\begin{array}{c}16(40) \\
13(32.5) \\
11(27.5)\end{array}$ & $\begin{array}{c}2(10) \\
8(40) \\
10(50)\end{array}$ & $\begin{array}{l}14(70) \\
5(25) \\
1(5)\end{array}$ & $\begin{array}{l}\mathbf{0 . 0 0 1} \\
0.311 \\
\mathbf{0 . 0 0 2}\end{array}$ \\
\hline $\begin{array}{l}\text { Avascular area score } \\
\text { Score } 0 \\
\text { Score } 1 \\
\text { Score } 2 \\
\text { Score } 3 \\
\end{array}$ & $\begin{array}{c}10(25) \\
14(35) \\
7(17.5) \\
11(27.5) \\
\end{array}$ & $\begin{array}{c}0(0) \\
5(25) \\
6(30) \\
10(50)\end{array}$ & $\begin{array}{c}10(50) \\
9(45) \\
1(5) \\
1(5) \\
\end{array}$ & $\begin{array}{l}\mathbf{0 . 0 0 1} \\
0.185 \\
\mathbf{0 . 0 3 7} \\
\mathbf{0 . 0 0 2} \\
\end{array}$ \\
\hline $\begin{array}{l}\text { Telangiectasia score } \\
0 \\
1 \\
2 \\
\end{array}$ & $\begin{array}{c}13(32.5) \\
19(47.5) \\
8(20) \\
\end{array}$ & $\begin{array}{l}2(9.5) \\
10(50) \\
8(40) \\
\end{array}$ & $\begin{array}{c}11(57.9) \\
9(45) \\
0(0) \\
\end{array}$ & $\begin{array}{l}\mathbf{0 . 0 0 2} \\
0.752 \\
\mathbf{0 . 0 0 4} \\
\end{array}$ \\
\hline $\begin{array}{l}\text { NFC score } \\
\text { Score } 0 \\
\text { Score } 1 \\
\text { Score } 2 \\
\text { Score } 3 \\
\end{array}$ & $\begin{array}{l}13(32.5) \\
11(27.5) \\
7(17.5) \\
9(22.5) \\
\end{array}$ & $\begin{array}{l}2(10) \\
3(15) \\
6(30) \\
9(45)\end{array}$ & $\begin{array}{l}11(55) \\
8(40) \\
1(5) \\
0(0)\end{array}$ & $\begin{array}{l}\mathbf{0 . 0 0 2} \\
\mathbf{0 . 0 7 7} \\
\mathbf{0 . 0 3 7} \\
\mathbf{0 . 0 0 2}\end{array}$ \\
\hline
\end{tabular}

SSc: systemic sclerosis, PAH: pulmonary artery hypertension, NFC: nail fold capillaroscopy.

Correlating the mean PAP with various demographic, clinical data and NFC changes documented a significant correlation between PAP with the disease duration $(\mathrm{r}=0.52$, ) and telangiectasia $(\mathrm{r}=0.49)$ together with significant negative correlation regarding capillary density ( $\mathrm{r}=-0.57)$ (Figures 3 ).
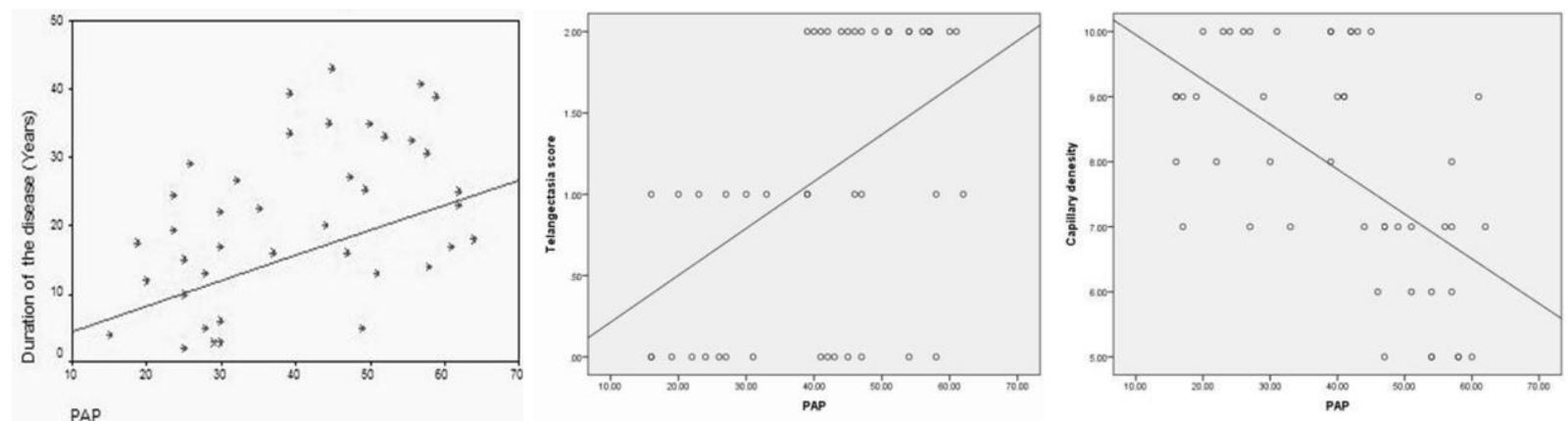

Figure 3: Significant correlation between the mean pulmonary arterial pressure (PAP) with disease duration (left), telangiectasia score (middle) and inversely with the capillary density score (right) in systemic sclerosis. 


\section{DISCUSSION}

Pulmonary arterial hypertension is a lethal complication with bad prognostic value that affects $10-15 \%$ of patients with SSc and even with advances in treatment still accounts for significant morbidity and mortality ${ }^{(23)}$. PAH is marked by increased resistance of pulmonary vessels because of remodeling and obstruction of pulmonary arterioles with subsequent increase of the mean pulmonary artery pressure (PAP) $>25 \mathrm{mmHg}$ at rest or $>30$ $\mathrm{mmHg}$ during exercise, without raised pulmonary capillary wedge pressure (measured by right heart catheterization (RHC) ${ }^{(24)}$. The majority of patients are usually presented with serious manifestations, marked functional distortion, severe hemodynamic impairment, resulting in poor outcome. So, early screening through systematic evaluation of asymptomatic individuals can diagnose PAH at an early stage for better physical outcomes ${ }^{(25)}$.

Isolated PH occurs as a late-stage complication after about 20 years from the onset of SSc ${ }^{(26)}$. Similarly, our study reported that SSc patients with PAH have significantly a longer disease duration than those without, which was in agreement with previous studies $\mathbf{( 9 , 2 6 )}$. According to the extent of skin fibrosis, patients with PAH were more of the limited subtype (lcSSc). This was similar to Chang et al. (26) and Walker et al. ${ }^{(27)}$ who found that the PAH happened more in lcSSc than in dcSSc. Patients with PAH had significantly more evident peripheral vascular manifestations in the form of Raynaud's phenomenon, telangiectasia, digital ulcers, and pitting scars. This comes according to previous studies $(9,26,27)$ who documented Raynaud's phenomenon, multiple telangiectasia's, and digital ulceration as important clinical manifestations linked to higher risk of developing PAH in the setting of SSc.

Serological biomarkers have been suggested to have a better predictive value for the occurrence of PAH than conventional clinical risk factors ${ }^{(9)}$. The current study revealed that patients with $\mathrm{PAH}$ had more positivity of both anti-centromere and anti-Scl70 antibodies together with a significantly higher ESR level. In agreement, Elshereef et al. (9) found significant differences in the level of ESR, complement, and anti-centromere antibodies in patients with PAH versus those without. Furthermore, Walker et al. (27) documented that $\mathrm{PH}$ without pulmonary fibrosis was more common in those with anti-centromere versus anti-Scl-70 antibodies (13 vs. $5 \%)$.

Nailfold capillaroscopy (NFC) is a highly sensitive, inexpensive, simple, safe, and non-invasive imaging technique used to analyze the morphology of nourishing capillaries in the nailfold area ${ }^{(\mathbf{2 8})}$. Marked by its presence in the most recent ACR/EULAR consensus classification criteria, NFC has shown to predict disease activity, many organ-target complications like digital ulcers, pulmonary hypertension, interstitial lung disease, and even death (29). Because of the relatively lower occurrence of PAH than other organ-specific manifestations, it is harder to investigate the role of NFC in predicting its existence or severity. In a Dutch group of over 200 patients, NFC changes were separately predictive of cardio-respiratory complications and interestingly, all patients with pulmonary hypertension had abnormal NFC picture ${ }^{(24)}$.

On studying the frequency of NVC scleroderma pattern (early, active, and late), patients without PAH showed an earlier pattern of capillary abnormalities in comparison with those with. While, those with PAH had an increased number of late scleroderma pattern. This was in agreement with the findings of Riccieri $\boldsymbol{e t}$ al. ${ }^{(30)}$ and Reyes-Rueda et al. ${ }^{(31)}$, in which late and active patterns were more frequent among patients with PAH. On the other hand, a study by Greidinger et al. (32) found no variations in capillary patterns between SSc with and without PAH. Moreover, the present study revealed that patients with $\mathrm{PAH}$ had a lower capillary density, increased capillary width, increased number of dilated mega-capillaries together with increased areas of capillary hemorrhages and areas of sub-capillary venous plexuses in comparison to those without. Similarly, Ong et al. ${ }^{(33)}$ found a significant reduction of capillary density in SSc patients with $\mathrm{PAH}$ in contrast to those without. Also, Corrado et al. ${ }^{(13)}$ reported that patients with PAH had a significantly lower capillary density and higher capillary width compared to SSc patients without. Furthermore, Hofstee et al. ${ }^{(14)}$ stated a lower capillary density in those with $\mathrm{PAH}$, however, loop dimensions were comparable.

A report enrolling patients with idiopathic $\mathrm{PAH}$ showed no differences in capillary densities or patterns compared to healthy controls. However, a reduction of capillary density in both SSc associated and idiopathic PAH was found, albeit to a milder extent in the latter ${ }^{(14)}$. A suggested explanation for the more profound capillary reduction in SSc patients with PAH may be due to the PAH itself which amplifies the reduction of capillary density already existing in SSc. Another explanation is the decrease in the density of capillaries may differ among the two diseases. In SSc, changes in the structure of the systemic microcirculation are generally assumed to occur before the pulmonary circulation changes, since systemic microvascular changes can occur several years before SSc develops ${ }^{(34)}$

Also, the current study reported that nearly $75 \%$ of patients with $\mathrm{PAH}$ had an avascular area score $\geq 2$ in contrast to $10 \%$ in those without. Also, about $73 \%$ of SSc with associated PAH had a total NFC score $\geq 2$ compared to $5 \%$ in those without. In accordance, Riccieri et al. ${ }^{(30)}$ reported NVC abnormalities among 
SSc patients with PAH scoring $>1$ and avascular area score $\geq 1$ were present in $83 \%$ compared to $11 \%$ in patients without. Moreover, Reyes-Reuda et al. ${ }^{(31)}$ found on NFC examination higher score of abnormalities among patients with PAH in contrast to those without and avascular area of score 3 was more frequently present among patients with PAH. Therefore, NVC changes might reveal what is going on in the pulmonary circulation supporting the hypothesis that structural changes in the microcirculation may be related to those vascular abnormalities presenting in the pulmonary circulation. The common loss of capillaries at nailfold and pulmonary bed may be in a similar pathway ${ }^{(35)}$. This may not be true for all capillary abnormalities, because most patients with SSc show NFC abnormalities whereas only a minority develops PAH. Although the great loss of capillaries may be due to PAH itself, a condition able to augment the reduction of vascularity. Thus NVC findings seem to reflect what occurred in the pulmonary circulation, with reduced capillary density and broad avascular areas signifying disease severity and organ involvements in $\mathrm{SSc}{ }^{(36)}$.

Correlating the mean PAP with various demographic, clinical data and NFC changes documented a significant correlation with disease duration, telangiectasia score and inversely with the capillary density score. In accordance, Elshereef $\boldsymbol{e t}$ $\boldsymbol{a l}^{\left({ }^{(9)}\right.}$ found a significant correlation between PAP and disease duration. Also, Hofstee et al. ${ }^{(14)}$ revealed that capillary density correlated with mean PAP at rest in SSc patients with PAH. Moreover, Riccieri et al. ${ }^{(30)}$ reported significant correlations between pulmonary pressure values with NVC and with the avascular areas score. Conversely, Reyes-Rueda et al. ${ }^{\left({ }^{(31)}\right.}$ found no correlation between abnormal capillaroscopy with pulmonary hypertension.

Limitations of the current study is that not all received medications were investigated. Also, the study included a relatively small number of patients. Larger cohorts with longitudinal study design are recommended in future studies.

In conclusion, low capillary density together with wide avascular areas and more severe scores were associated with the presence of PAH indicating that either systemic microvascular changes play a role in the development of $\mathrm{PAH}$, or that PAH itself amplifies the systemic microvascular impairment constantly detectable in SSc. So, a complete NVC study seems to be a helpful simple screening tool required for all SSc patients to identify those at risk for PAH in a very early phase of the disease for a proper diagnosis and intervention. Special consideration should be given to those with long disease duration, evident peripheral microvascular manifestations, and positive auto-antibodies. Therapeutic clinical trials with NVC monitoring to measure the treatment outcome for SSc with $\mathrm{PAH}$ should be considered in future studies.

\section{Conflict of interest: none}

Funding: This research did not receive any specific grant from funding agencies in the public, commercial, or not-for-profit sectors.

\section{REFERENCES}

1. Sobolewski P, Maślińska M, Wieczorek M, Tagun Z, Malewska A, Roszkiewicz M et al. (2019): Systemic sclerosis - multidisciplinary disease: clinical features and treatment. Reumatologia, 57(4):221-33.

2. Pattanaik D, Brown M, Postlethwaite BC, Postlethwaite AE (2015): Pathogenesis of systemic sclerosis. Front. Immunol., 6:272.

3. Hummers L, Wigley F (2013): Scleroderma. In: Current diagnosis and treatment: rheumatology. Imboden JB, Hellmann DB, Stone JH (Ed.).The McGraw-Hill Companies, Pp:1738-40.

4. Elsayed AM, Elhefny AM, Abogabal MM, Mobasher SA, AmrAbdelzaher A, Alhassanein KF et al. (2018): Progressive systemic sclerosis in Egyptian patients: Clinical characteristics and nail fold capillaroscopy. The Egyptian Rheumatologist, 41(1) : 47-51

5. Kubo S, Smith V, Cutolo M, Tanaka Y (2018): The role of nailfoldvideocapillaroscopy in patients with systemic sclerosis. Immunological Medicine, 41:113-9.

6. Hafez EA, Hamza SH, Morad CS, AbdAlkader AA (2018): Pulmonary manifestations in Egyptian patients with systemic sclerosis. The Egyptian Rheumatologist, 40(1): 39-44

7. Farag NA, El Serougy EM, Metawee SA, El Azizi HS (2015): Subclinical atherosclerosis and peripheral vascular disease in systemic sclerosis patients: Relation to potential risk factors. The Egyptian Rheumatologist, 37(1):23-28.

8. Simonneau G, Robbins IM, Beghetti M, Channick RN, Delcroix M, Denton CP et al. (2009): Updated clinical classification of pulmonary hypertension. J Am CollCardiol., 54(1):43-54

9. Elshereef RR, A Hassan AA, Darwish AD, Asklany HT , Hamdy L (2013): Pulmonary hypertension in scleroderma and its relation to disease activity. Egyptian Rheumatology Rehabilitation, 40 (4): 173-80.

10. Davie NJ, Schermuly RT, Weissmann N, Grimminger F, Ghofrani HA (2009): The science of endothelin-1 and endothelin receptor antagonists in the management of pulmonary arterial hypertension: current understanding and future studies. European $\mathbf{J}$ Clin Inv., 39 (2): 38-49.

11. Sulli A, Soldano S, Pizzorni C, Montagna P, Secchi ME, Villaggio B et al. (2009): Raynaud's phenomenon and plasma endothelin: correlations with capillaroscopic patterns in systemic sclerosis. J Rheumatol., 36(6):1235-9.

12. Rajaei A, Dehghan P, Delkash P (2016): Reporting microvascular changes in nail fold capillaroscopy: A narrative review. http://www.rheumres.org/article_42084.html

13. Corrado A, Correale M, Mansueto N (2017): Nailfold capillaroscopic changes in patients with idiopathic pulmonary arterial hypertension and systemic sclerosis- 
related pulmonary arterial hypertension. Microvasc Res., 114: 46-51.

14. Hofstee HM, VonkNoordegraaf A, Voskuyl AE, Dijkmans BA, Postmus PE, Smulders YM et al. (2009): Nailfold capillary density is associated with the presence and severity of pulmonary arterial hypertension in systemic sclerosis. Ann Rheum Dis., 68(2):191-5

15. Van den Hoogen F, Khanna D, Fransen J, Johnson S, Baron M, Tyndall A et al. (2013): classification criteria for systemic sclerosis: an American college of rheumatology/european league against rheumatism collaborative initiative. Arthritis Rheum., 65(11):273747

16. Le Roy EC, Black C, Fleischmajer R, Jablonska S, Krieg T, Medsger TA et al. (1988): Scleroderma (systemic sclerosis): classification, subsets and pathogenesis. J Rheumatol., 15:202-205

17. Rudski LG, Lai WW, Afilalo J, Hua L, Hands chumacher MD, Chandrasekaran K et al. (2010): Guidelines for the Echocardiographic Assessment of the Right Heart in Adults: A Report from the American Society of Echocardiography Endorsed by the European Association of Echocardiography, a registered branch of the European Society of Cardiology, and the Canadian Society of Echocardiography. J Am Soc Echocardiogr., 23:685-713.

18. Brennan JM, Blair JE, Goonewardena S, Ronan A, Dipak Shah D, Vasaiwala S et al. (2007): Reappraisal of the use of inferior vena cava for estimating right atrial pressure. J Am Soc Echocardiogr., 20(7):857-61.

19. Galiè N, Humbert M, Vachiery JL, Gibbs $S$, Lang I, Torbicki A et al. (2015): 2015 ESC/ERS Guidelines for the diagnosis and treatment of pulmonary hypertension. The Joint Task Force for the Diagnosis and Treatment of Pulmonary Hypertension of the European Society of Cardiology (ESC) and the European Respiratory Society (ERS). Eur Respir J., 46: 903-975.

20. Maricq HR (1981): Widefield capillary microscopy: technique and rating scale for abnormalities seen in scleroderma and related disorders. Arthritis Rheum., 24:1159-65.

21. Cutolo M, Sulli A, Pizzorni C, Accardo S (2000): Nailfold videocapillaroscopy assessment of microvascular damage in systemic sclerosis. J Rheumatol., 27:155-60.

22. Lee P, Leung FY, Alderdice C, Armstrong SK (1983): Nailfold capillary microscopy in the connective tissue diseases: a semiquantitative assessment. J Rheumatol., 10: 930-8.

23. Parker MJS, McGill NW (2018): The Established and Evolving Role of Nailfold Capillaroscopy in Connective-Tissue Disease. Available from: https://www.intechopen.com/online-first/theestablished-nd-evolving-role-of-nailfoldcapillaroscopy-in-connective-tissue-disease.

24. McLaughlin VV, Archer SL, Badesch DB, Barst RJ, Farber HW, Lindner JR et al. (2009): ACCF/AHA 2009 expert consensus document on pulmonary hypertension a report of the American College of Cardiology Foundation Task Force on Expert Consensus Documents and the American Heart
Association developed in collaboration with the American College of Chest Physicians; American Thoracic Society, Inc.; and the Pulmonary Hypertension Association, J Am Coll Cardiol., 53:1573-619.

25. Weatherald J, Montani D, Jevnikar M, Jaïs $X$, Savale L, Humbert M (2019): Screening for pulmonary arterial hypertension in systemic sclerosis. European Respiratory Review, 28: 190023.

26. Chang B, Schachna L, White B, Wigley FM, Wise RA (2006): Natural history of mild-moderate pulmonary hypertension and the risk factors for severe pulmonary hypertension in scleroderma. J Rheumatol., 33: 269-274.

27. Walker UA, Tyndall A, Czirják L, Denton C, FargeBancel D, Kowal-Bielecka O et al. (2007): Clinical risk assessment of organ manifestations in systemic sclerosis: a report from the EULAR Scleroderma Trials and Research group database. Ann Rheum Dis., 66 :754763.

28. Lambova SN, Müller-Ladner U (2018): Mosaic capillaroscopic findings in systemic sclerosis. Wiener Medizinische Wochenschrift, 168: 248-9.

29. Markusse IM, Meijs J, de Boer B, Bakker JA, Schippers HPC, Schouffoer AA et al. (2017): Predicting cardiopulmonary involvement in patients with systemic sclerosis: complementary value of nailfoldvideocapillaroscopy patterns and diseasespecific autoantibodies. Rheumatology (Oxford), 156:1081-8.

30. Riccieri V, Vasile M, Iannace N, Stefanantoni K, Sciarra I, Vizza CD et al. (2013): Systemic sclerosis patients with and without pulmonary arterial hypertension: a nailfold capillaroscopy study. Rheumatology, 52( 8):1525-8.

31. Reyes-Rueda J, Gutierrez-Ureña SR, Gonzalez-Díaz V, Martínez-Bonilla G, Garcia-Osuna KM, Cardona-Muller D et al. (2018): Abnormal capillaroscopy and pulmonary hypertension in patients with systemic sclerosis. DOI: 10.1136/annrheumdis2018-eular.6133.

32. Greidinger EL, Gaine SP, Wise RA, Boling C , Housten-Harris T, Wigley FM (2001): Primary pulmonary hypertension is not associated with scleroderma-like changes in nailfold capillaries. Chest, 120(3):796-800.

33. Ong YY, Nikoloutsopoulos T, Bond CP (1997): Decreased nailfold capillary density in limited scleroderma with pulmonary hypertension. Asian Pac J Allergy Immunol., 16(2-3):81-6.

34. Cutolo M, Sulli A, Pizzorni C, Smith V (2010): Capillaroscopy as an Outcome Measure for Clinical Trials on the Peripheral Vasculopathy in SSc-Is It Useful? Int J Rheumatology, 69(6):1092-1096.

35. Herrick AL, Moore TL, Murray AK, Whidby N, Manning JB, Bhushan M et al. (2010): Nail-fold capillary abnormalities are associated with anticentromere antibody and severity of digital ischemia, Rheumatology, 49:1776-82.

36. Ingegnoli F, Ardoino I, Boracchi P, Cutolo M (2013): Nailfoldcapillaroscopy in systemic sclerosis: data from the EULAR scleroderma trials and research (EUSTAR) database. Microvasc Res., 89:122-128. 